Cinémas

Revue d'études cinématographiques

Journal of Film Studies

\title{
GAUDREAULT, André et JOST, François. Le Récit cinématographique. Éditions Nathan, Collection Nathan-Université, 1990, 159 p.
}

\section{Jean-Claude Jaubert}

Volume 1, numéro 3, printemps 1991

URI : https://id.erudit.org/iderudit/1001072ar

DOI : https://doi.org/10.7202/1001072ar

Aller au sommaire du numéro

Éditeur(s)

Cinémas

ISSN

1181-6945 (imprimé)

1705-6500 (numérique)

Découvrir la revue

Citer ce compte rendu

Jaubert, J.-C. (1991). Compte rendu de [GAUDREAULT, André et JOST, François. Le Récit cinématographique. Éditions Nathan, Collection Nathan-Université, 1990, 159 p.] Cinémas, 1(3), 151-153. https://doi.org/10.7202/1001072ar d'utilisation que vous pouvez consulter en ligne.

https://apropos.erudit.org/fr/usagers/politique-dutilisation/ 
GAUDREAULT, André et JOST, François. Le Récit cinématographique. Éditions Nathan, Collection Nathan-Université, 1990, 159 p.

Les études théoriques sur le cinéma ont pris, au cours de la dernière décennie, une orientation quelque peu différente des études sémiologiques des années 70 , emmenées principalement par Christian Metz et ses disciples. C'est aujourd'hui la narratologie, soit l'étude du récit, qui mobilise les chercheurs et progresse rapidement. Comme ce fut le cas autrefois pour la sémiologie du cinéma, on est parti de recherches appliquées au texte écrit pour explorer le mécanisme du récit cinématographique.

Le petit livre que publie aujourd'hui les éditions Nathan, sous le titre Le Récit cinématographique, est le fruit d'une collaboration fructueuse entre deux universitaires et théoriciens qui ont chacun de leur côté beaucoup réfléchi et écrit sur la formation et l'évolution du récit au cinéma.

André Gaudreault, de l'Université Laval apporte à cette analyse des dispositifs narratifs du cinéma ses connaissances du "cinéma des premiers temps», comme on appelle maintenant l'œuvre des pionniers des débuts du cinéma. Son travail dans le présent livre est une suite et un complément au livre qu'il a publié deux ans auparavant sous le titre Du littéraire au filmique, système du récit, aux Presses de l'Université Laval/Méridiens Klincksieck.

François Jost, de la Sorbonne Nouvelle, est passé de l'étude du Nouveau Roman et plus spécialement de la question du récit dans les œuvres des grands maîtres de ce nouveau genre aux questions de narration dans le cinéma en y transposant et développant les recherches de Gérard Genette sur la narratologie.

Un livre à quatre mains donc, concis et clair, que je considère comme un manuel d'introduction au système du récit cinématographique, tant il est conçu avec la volonté d'être simple et concret.

J'insisterais d'ailleurs davantage sur la notion de concret que de simplicité. Traiter de narratologie oblige en effet à utiliser une terminologie sans cesse en évolution, en création, qui aide à cerner des concepts toujours plus pointus. Les auteurs ont choisi d'aborder de front cette terminologie mise au point par les Genette, Todorov et autres dans le domaine du récit écrit et, à l'occasion, par eux-mêmes et par d'autres dans le domaine du cinéma, et de l'expliquer le plus clairement possible en illustrant le plus souvent le concept analysé par un exemple de plan ou de scène tirée d'un film classique, puis de l'utiliser dans le cours de 
leurs explorations/explications. Ainsi, si même les néophytes en matière de théorie cinématographique manipulent aujourd'hui sans difficulté un terme comme diégèse (en abrégé : tout ce qui appartient au monde proposé ou raconté par la fiction), il n'en est certainement pas de même pour des termes comme «analepse» ou «prolepse», empruntés à Genette et employés pour décrire ce que ces mêmes néophytes avaient l'habitude d'appeler des flash-back et des flash-forward. Présentée ainsi, hors de son cadre d'utilisation, le choix de cette terminologie savante peut paraître inutile, mais il faut rendre justice aux auteurs du livre qui savent convaincre leur lecteur qu'on ne peut se passer d'elle pour la juste compréhension du phénomène et qu'elle n'est après tout pas si difficile à maîtriser.

Partant de la scène d'exposition bien connue du film Citizen Kane, dont cinq photogrammes essentiels sont donnés en appendice, les auteurs posent donc les paramètres de leur étude: comment est-ce que le cinéma (image, texte, paroles et sons ) procède pour raconter quelque chose? Qui raconte dans un film? Comment s'y prennent les cinéastes pour maîtriser le temps? Et d'autres questions encore, qui ne sont pas nouvelles certes mais qui sont abordées d'une façon nouvelle aujourd'hui.

Cette interrogation du fonctionnement du cinéma, on l'appelait auparavant, l'étude du langage cinématographique, et le bon vieux manuel de Marcel Martin, dans la collection $7 \mathrm{e}$ art des Éditions du Cerf, intitulé Le Langage cinématographique, procédait déjà au «recensement méthodique de tous les procédés d'expression et de langage utilisés par le cinéma» (p. 15). La différence avec le travail réalisé aujourd'hui par nos auteurs est méthodologique. Ce ne sont plus les «procédés» qui guident la progression mais l'exploration des différentes composantes du récit cinématographique.

Vu la complexité narrative d'un seul plan de film, qui peut comprendre plusieurs couches superposées d'énoncés narratifs, le détour par la simplicité relative du cinéma des premiers temps est une aide appréciable. Il y a loin de L'Arroseur arrosé à Citizen Kane, pourtant il suffit de suivre les explications et démonstrations que nous proposent Gaudreault et Jost pour franchir «sans peine» (comme on dit «l'anglais sans peine») les étapes qui séparent «narrativement» les deux films.

Après un bref chapitre d'introduction dans lequel ils situent leurs recherches au sein de la narratologie en général, nos auteurs définissent ce qu'est un récit «tout court», puis s'attachent à cerner, dans le premier chapitre, la spécificité du récit cinématographique. Les cinq chapitres suivant exploreront dans le détail, 
et avec de très nombreux exemples, les grands axes de cette spécificité. Le chapitre «Énonciation et narration» est la base de l'édifice. «L'énonciation cinématographique [serait] ce moment où le spectateur s'échappant de l'effet-fiction aurait la conviction d'être en présence du langage cinématographique», au moment donc où il perdrait cette impression que le récit qui se déroule sous ses yeux se raconte tout seul, sans intervention d'un narrateur décelable. Il suffit de suivre les exemples analysés dans ce chapitre pour découvrir les multiples déguisements, incarnations et délégations du narrateur cinématographique.

«Le mot et l'image» nous propose une évolution de la narration verbale et écrite au cinéma qui serait passée de l'usage du mot verbal, sous le règne des «bonimenteurs", au mot écrit (cartons et intertitres), durant la période «classique» du cinéma muet, pour arriver à la parole et aux sons du cinéma sonore. Cette présence du «bonimenteur», que l'on a souligné dans le cinéma japonais (le traditionnel benshi), avait peu attiré l'attention des historiens des cinémas occidentaux. Ce bonimenteur servait de «narrateur-suppléant» et «comblait les trous de la narration filmique».

Les trois derniers chapitres traitent respectivement de l'espace, du temps et du point de vue dans le récit cinématographique. Chapitres également illustrés d'exemples de films connus et de graphiques explicatifs. Comme tous les autres, ces chapitres se terminent par une bibliographie se rapportant directement aux notions abordées dans le cours du chapitre.

À la fin du volume, une bibliographie générale reprend, par ordre alphabétique d'auteur, les titres déjà cités dans les bibliographies de chapitre. Cette bibliographie, les nombreux photogrammes illustrant les exemples de films les plus souvent utilisés, le nombre important de films mentionnés à un moment ou à l'autre de l'étude, les graphiques illustrant les explications les plus complexes justifient largement l'appellation de «manuel» que j'ai donnée à ce livre. Je suis étonné d'ailleurs que, pour faciliter encore davantage cet usage didactique, les auteurs, ou l'éditeur, n'aient pas songé à ajouter un glossaire, ou tout au moins un index, des termes et des notions employés et expliqués au cours du livre.

Un ouvrage de synthèse comme celui-ci sera particulièrement précieux pour les enseignants, les étudiants en cinéma, mais aussi tous ceux qui désirent comprendre mieux comment fonctionnent les mécanismes du récit cinématographique.

Jean-Claude Jaubert

Université York 